\title{
METABOLIC SYNDROME PATIENT COMPLIANCE WITH DRUG TREATMENT
}

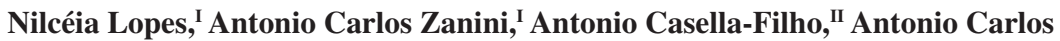 \\ Palandri Chagas ${ }^{\text {II }}$
}

doi: $10.1590 / \mathrm{S1807-59322008000500002}$

Lopes N, Zanini AC, Casella-Filho A, Chagas ACP. Metabolic syndrome patient compliance with drug treatment. Clinics. 2008;63(5):573-80.

OBJECTIVES: 1) To evaluate the compliance with drug treatment in patients with metabolic syndrome. 2) To determine association between access to and use of medicines, as well as the level of knowledge of cardiovascular risk factors and compliance.

INTRODUCTION: Low compliance has been one of the greatest challenges for the successful treatment of chronic diseases. Although this issue has been widely studied in patients with isolated hypertension, diabetes and dyslipidemia, compliance studies involving patients with these concomitant diseases or with metabolic syndrome diagnosis are scarce.

METHODS: This was a cross-sectional study involving patients who have been diagnosed with metabolic syndrome according to the IDF criteria. Patients were being treated in a Health-Medical School Center bound to the Public Brazilian Healthcare System. This study was conducted in two phases. Phase I was characterized by analyzing medical records and Phase II involved interviewing the patients. A variation of the Morisky-Green Test was used to evaluate compliance. Compliance was the dependent variable and the independent variables included access to medicines, the use of medicines and the level of knowledge concerning cardiovascular risk factors.

RESULTS: Two hundred and forty-three patients were identified as being eligible for Phase II, and 75 were included in the study. The average level of compliance was 5.44 points (standard deviation of 0.68 ), on a scale ranging from 1.00 to 6.00 points. There was no statistically meaningful association between independent variables and compliance. The level of patient knowledge of diet and dyslipidemia was considered to be low.

CONCLUSIONS: Patients involved in this study exhibited a high level of compliance with drug treatment. Further research is needed to better elucidate the compliance behavior of patients who have been diagnosed with metabolic syndrome.

KEYWORDS: Adherence; Hypertension; Diabetes; Abdominal obesity; Drug utilization.

\section{INTRODUCTION}

In recent years metabolic syndrome has aroused universal interest from the scientific community ${ }^{1}$ as well as healthcare managers. ${ }^{2}$ This condition is highly prevalent in both developed ${ }^{3}$ and emerging countries. ${ }^{4}$ It involves both young and elder persons ${ }^{3,5}$ and it is associated with an increased

IDepartment of Pharmacy, Faculdade de Ciências Farmacêuticas da Universidade de São Paulo (USP) - São Paulo/SP, Brazil.

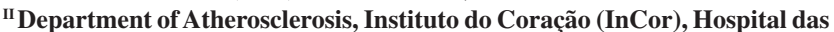
Clínicas, Faculdade de Medicina, Universidade de São Paulo (FMUSP) - São Paulo/SP, Brazil.

Phone: 55113091.3668

Email: nilceias@yahoo.com

Received for publication on March 9, 2008

Accepted for publication on June 11, 2008 risk of diabetes, cardiovascular morbidity and mortality. ${ }^{6-7}$ The main goal of treatment for metabolic disease is to reduce cardiovascular risk. ${ }^{8}$ Although lifestyle change is the first line of therapy, many patients require integrated drug treatment. ${ }^{8,9}$ Even in the absence of the clinical manifestation of atherosclerotic cardiovascular disease or diabetes, any person with metabolic syndrome should undergo Framingham risk scoring. ${ }^{10,11}$

Low patient compliance has been one of the greatest challenges for success in the treatment of chronic diseases such as hypertension, dyslipidemia and diabetes, even when they appear as isolated entities. ${ }^{12,13}$ In practice, the treatment of metabolic syndrome implies the sum of difficulties usually found in monitoring each one of its components. According to the World Health Organization, patient 
compliance with treatment is defined as the extent to which a person's behavior - taking medication, following a diet and/or executing lifestyle changes - corresponds with the recommendations from the healthcare provider. ${ }^{14}$

Although this issue has been widely studied in patients with isolated hypertension, diabetes and dyslipidemia, ${ }^{15-17}$ compliance studies involving patients with these concomitant diseases or with metabolic syndrome diagnosis are scarce. To assess patient compliance with drug treatment for metabolic syndrome, a cross-sectional study was performed. This study also had the objective of determining the association between access to and the use of medicines, as well as the level of knowledge of cardiovascular risk factors and patient compliance with drug treatment.

\section{METHODS}

This cross-sectional study included patients who had been diagnosed with metabolic syndrome and who were being treated in a Health-Medical School Center attached to the Public Brazilian Healthcare System (SUS).

This study was conducted in two phases. Phase I was characterized by the analysis of medical records, aimed at identifying those patients who showed evidence of metabolic syndrome according to the International Diabetes Federation (IDF) criteria: ${ }^{18}$ waist circumference - ethnicity specific values (males $\geq 90 \mathrm{~cm}$ and for females $\geq 80 \mathrm{~cm}$ ) as a measure of central obesity, plus any two of the following: (a) raised triglyceride levels ( $\geq 150 \mathrm{mg} / \mathrm{dl}$, or specific treatment for this lipid abnormality); (b) reduced HDL-cholesterol levels $(<40 \mathrm{mg} / \mathrm{dl}$ in males and $<50 \mathrm{mg} / \mathrm{dl}$ in females, or specific treatment for this lipid abnormality); (c) raised blood pressure (systolic $\geq 130 \mathrm{mmHg}$ or diastolic $\geq 85 \mathrm{mmHg}$, or treatment of previously diagnosed hypertension); (d) raised plasma glucose (fasting plasma glucose $\geq 100 \mathrm{mg} / \mathrm{dl}$, or previously diagnosed type 2 diabetes). If the Body Mass Index was $>30 \mathrm{~kg} / \mathrm{m}^{2}$, central obesity was assumed and waist circumference was not measured. ${ }^{18}$

In Step 1, patients who were diagnosed with hypertension and/or diabetes were identified. Subsequently (Step 2), patient data concerning all components of metabolic syndrome was collected, according to the availability of medical records. This step considered the diagnosis specified on the medical records, the prescription of medicines for the treatment of each component of metabolic syndrome and finally the results of clinical and laboratory tests.

In Step 3, obese and overweight patients were selected according to their Body Mass Index (BMI). In Step 4, data records were analyzed regarding the presence of other metabolic syndrome components in the overweight or obese patients. Among patients identified in Step 4, those who were between 18 and 70 years of age and on drug treatment for at least one of the metabolic syndrome components were selected to participate in Phase II. Those who had totally or partially restricted verbal communication (specified in the medical records) were excluded.

In Phase II, patients who were identified in Phase I and showed evidence of metabolic syndrome were called in to be interviewed to confirm their diagnosis, evaluate compliance with drug treatment and determine the associations between the analyzed variables.

Interviews were scheduled by phone and conducted personally, using a structured questionnaire addressing the following aspects: (i) socio-demographic patient profile; (ii) access to and use of medicines; (iii) knowledge of cardiovascular risk factors based on the study by Kahn et al. ${ }^{19}$; (iv) assessment of patient compliance with drug treatment using the Measure Treatment Adherence (MTA) Scale developed by Delgado and Lima. ${ }^{20}$ Drug treatment encompassed integrated management with antihypertensive, antidiabetic and antilipemic agents. The MTA Scale, a variation of the Morisky-Green Test with seven questions, was used to assess patient behavior patterns associated with the use of medicines..$^{20}$ The MTA Scale consists of the following questions: (1) Have you ever forgotten to take your medicines?; (2) Were you careless at times about taking your medicines?; (3) When you felt better, did you sometimes stop taking your medicines?; (4) Sometimes, if you felt worse, did you stop taking your medicines?; (6) Have you ever discontinued treatment because you ran out of pills?; (7) Have you ever stopped taking your medicines for any reason other than a medical advisory? The MTA Scale allows answers from "always" to "never," with scores ranging from 1 to 6 points. The highest values indicate the highest level of compliance with drug treatment. ${ }^{20}$

During the interviews, to confirm diagnosis, patients were asked about the time of diagnosis of each metabolic syndrome component and the treatment recommendation. The following anthropometric measurements were also performed: weight, height and waist circumference. To measure weight in kilograms and height in meters, an anthropometric balance was used (Filizolla ${ }^{\mathrm{TM}}$, Campo Grande, MS, Brazil) with barefoot patients, wearing light clothes and looking at the horizon. The waist circumference, in centimeters, was measured on bare skin, mid-distance between the bottom of the rib cage and the top of the iliac crest ${ }^{21}$ using an inelastic tape.

Patient compliance was the dependent variable evaluated. The following variables were considered independent:

- Variables related to access to medicines (mode of acquisition of medicines, difficulty in getting prescriptions filled and expense of medicines compared to total family income); 
- Variables related to the use of medicines (number of medicines per day, number of tablets per day and daily dose frequency, responsibility for managing medicines and interference of patients' daily routine);

- Level of knowledge about cardiovascular risk factors.

Statistical analysis was performed by the Spearman coefficient and the Kruskal-Wallis or Mann-Whitney nonparametric tests. It was established that $p<0.05$ would be the limit for statistical significance and the software used was SPSS 15.0 for Windows (SPSS Inc., USA).

Analysis of medical records began in March 2007 and lasted two months. Interviews were conducted from May to July 2007.

This research was approved by the Committee of Ethics on October 30, 2006 (Protocol Number: 395). Only those patients who provided their written consent took part in this study.

\section{RESULTS}

\section{Patient Characteristics}

Table 1 summarizes the results of each step of medical record analysis and patient selection.

Among the 243 identified patients, 83 (34.2\%) scheduled an appointment for this study. The other $160(65.8 \%)$ patients could not schedule an appointment for the following reasons: $104(42.8 \%)$ could not be contacted due to difficulties with phone calls, 55 (22.6\%) did not agree to participate and one patient had died $(0.41 \%)$. Of the 83 scheduled patients, $8 \mathrm{did}$ not attend their appointment. As a result, 75 patients with confirmed metabolic syndrome diagnosis were included in this study. Table 2 presents the characteristics of the 243 identified patients.

Social-demographic characteristics. Among the 75 included patients, $41(54.66 \%)$ were women. Average

Table 1 - Results of each step of medical record analysis and patient selection

\footnotetext{
Step 1 - Electronic patients database analysis

550 records of diabetic and / or hypertensive patients

Step 2 - Data collection from medical records

483 medical records available

Step 3 - Selection of overweight or obese patients

56 medical records without information about obesity

60 patients with $\mathrm{BMI}^{*}<25 \mathrm{~kg} / \mathrm{m}^{2}$

367 overweight or obese patients (BMI $\geq 25 \mathrm{~kg} / \mathrm{m}^{2}$ or obesity diagnosis specified on medical notes)

Step 4 - Data analysis of other metabolic syndrome components 200 patients with diagnosis of $\mathrm{MS}^{\dagger}$ (BMI $\geq 30 \mathrm{~kg} / \mathrm{m}^{2}+2$ components)

144 patients with evidence of MS (132 with $25 \leq \mathrm{BMI} \leq 29.9 \mathrm{~kg} / \mathrm{m}^{2}$ and 12 with obesity diagnosis from medical notes +2 components)

In 23 cases it was not possible to suppose presence of MS with available data.

Step 5 - Other inclusion and exclusion criteria checked

101 patients excluded ( 1 without drug treatment and 100 older than 70 years)

243 patients identified for Phase II

* BMI = Body Mass Index. $\dagger$ MS = Metabolic Syndrome.
}

Table 2 - Clinical characteristics of 243 identified patients with evidence of metabolic syndrome, according to medical records

\begin{tabular}{|c|c|c|c|c|c|c|c|}
\hline & \multicolumn{3}{|c|}{$\begin{array}{l}\text { Identified patients who scheduled an } \\
\text { appointment to research }(n=83)\end{array}$} & \multicolumn{3}{|c|}{$\begin{array}{l}\text { Identified patients who did not schedule an } \\
\text { appointment to research }(n=160)\end{array}$} & \multirow[b]{2}{*}{$p$} \\
\hline & $n$ & Mean & $S D$ & $n$ & Mean & $S D$ & \\
\hline Weight(kg) & 83 & 82.7 & 16.7 & 160 & 81.3 & 16.2 & 0.530 \\
\hline Height $(\mathrm{cm})$ & 83 & 159.6 & 9.2 & 160 & 157.3 & 8.9 & 0.061 \\
\hline $\mathrm{BMI}^{*}\left(\mathrm{~kg} / \mathrm{m}^{2}\right)$ & 83 & 32.6 & 5.3 & 160 & 32.8 & 5.7 & 0.792 \\
\hline Triglycerides $(\mathrm{mg} / \mathrm{dl})^{* *}$ & 75 & 201.2 & 129.7 & 125 & 213.2 & 133.0 & 0.536 \\
\hline HDL-cholesterol $(\mathrm{mg} / \mathrm{dl})^{* *}$ & 13 & 47.0 & 7.7 & 14 & 47.4 & 8.8 & 0.905 \\
\hline Men & 06 & 41.5 & 8.4 & 03 & 44.3 & 7.6 & 0.699 \\
\hline Women & 07 & 51.7 & 2.1 & 11 & 48.6 & 10.6 & 0.491 \\
\hline $\mathrm{SBP}(\mathrm{mmHg}) \dagger$ & 71 & 144.0 & 24.6 & 139 & 143.5 & 20.8 & 0.878 \\
\hline $\mathrm{DBP}(\mathrm{mmHg}) \dagger$ & 71 & 87.7 & 13.5 & 139 & 88.5 & 12.5 & 0.671 \\
\hline Glycemic level $(\mathrm{mg} / \mathrm{dl}) \neq$ & 76 & 168.1 & 59.4 & 143 & 182.3 & 69.0 & 0.132 \\
\hline
\end{tabular}

SD: Standard deviation. Statistically significant: $p<0.05$ * Body Mass Index based on weight and height measurements from medical records from the last physician evaluation; **Triglycerides and HDL-cholesterol values from medical records from the last laboratory blood tests; $\uparrow$ Systolic and Diastolic Blood Pressure descriptive values from medical records from the last physician evaluation; $\ddagger$ Descriptive value of glycemic levels from medical records from the most recent laboratory blood tests. 
participant age was 63 years (minimum: 42 years; maximum: 70 years). There were $46(61.3 \%)$ married patients, 44 $(58.6 \%)$ patients were housewives or retired persons and 37 $(61.3 \%)$ patients were living with their spouse and children. With regard to level of education, 35 (46.7\%) patients had 4 years or less of elementary studies. The majority, i.e., 45 $(60.0 \%)$ participants, consisted of patients with a low family income (from R $\$ 415.00$ to R \$2,075.00 per months; R\$ 1.00 = US\$ 1.60). Regarding race, 37 (49.3\%) patients considered themselves white, 31 (41.3\%) were African-descendants, $4(5.33 \%)$ were Asian, $1(1.33 \%)$ was indigenous and 2 $(2.68 \%)$ did not answer this question.

Clinical characteristics. All 75 patients presented with a high waist circumference along with two more cardiovascular risk factors. Clinical characteristics of the patients are shown in Tables 3, 4 and 5.

Characteristics related to access and use of medicines. All patients received their medicines from the Public Brazilian Healthcare System, completely (42 patients; $56.0 \%$ ) or partially (33 patients, 44.0\%). Thirty-four
Table 5 - Distribution of frequencies of metabolic syndrome components, according to medical records of the 75 included patients

\begin{tabular}{lcc}
\hline Metabolic syndrome components & $\begin{array}{c}\text { Number of patients } \\
(\mathrm{n}=75)\end{array}$ & $\%$ \\
\hline HT + DM + Elevated TG & 41 & 54.7 \\
HT + DM & 25 & 33.3 \\
HT + Glucose Intolerance & 3 & 4.0 \\
HT + Glucose Intolerance + & 2 & 2.7 \\
Elevated TG & 2 & 2.7 \\
HT + DM + Elevated TG + Re- & 1 & 1.3 \\
duced HDL & & \\
HT + Elevated TG + Reduced & 1 & 1.3 \\
HDL & & \\
DM + Elevated TG &
\end{tabular}

HT: Hypertension diagnosis based on medical notes and prescription of antihypertensive drugs; DM: diagnosis of diabetes mellitus based on medical notes and prescription of antidiabetic agents; Elevated TG: triglycerides $\geq$ $150 \mathrm{mg} / \mathrm{dl}$ according to medical records from the last laboratory blood tests; Reduced HDL: HDL-cholesterol $\leq 40 \mathrm{mg} / \mathrm{dl}$ (for men) and $\leq 50 \mathrm{mg} / \mathrm{dl}$ (for women) according to medical records from the last laboratory blood tests.

Table 3 - Descriptive values of anthropometric measurements of the 75 included patients, according to medical records and at the time of inclusion

\begin{tabular}{|c|c|c|c|c|}
\hline \multirow[t]{2}{*}{ Anthropometric Measurement } & \multicolumn{2}{|c|}{ Medical records(n=75) } & \multicolumn{2}{|c|}{ Inclusion $(\mathrm{n}=75)$} \\
\hline & Mean & $\mathrm{SD}$ & Mean & $\mathrm{SD}$ \\
\hline Weight $(\mathrm{kg})$ & 83.1 & 17.4 & 84.6 & 17.3 \\
\hline Height $(\mathrm{cm})$ & 161.0 & 9.5 & 160.2 & 9.5 \\
\hline $\operatorname{BMI}\left(\mathrm{kg} / \mathrm{m}^{2}\right)$ & 32.3 & 5.4 & 32.8 & 5.3 \\
\hline \multicolumn{5}{|l|}{ Waist Circumference $(\mathrm{cm})$} \\
\hline $\operatorname{Men}(n=34)$ & NA & NA & 112.0 & 12.2 \\
\hline Women $(n=41)$ & NA & NA & 102.7 & 12.3 \\
\hline
\end{tabular}

SD: Standard deviation. BMI: Body Mass Index. NA: Not available.

Table 4 - Mean and standard deviation of clinical and laboratory tests of patients included in this study. Period of time between last medical records and at the time of patient inclusion in the study

\begin{tabular}{|c|c|c|c|c|c|}
\hline & \multicolumn{3}{|c|}{ Medical records } & \multicolumn{2}{|c|}{$\Delta \mathrm{T}$ (month)* } \\
\hline & $\mathrm{n}$ & Mean & SD & Mean & SD \\
\hline $\mathrm{SBP}(\mathrm{mmHg})^{* *}$ & 64 & 143.4 & 23.6 & 8.6 & 3.6 \\
\hline $\mathrm{DBP}(\mathrm{mmHg})^{* *}$ & 64 & 86.7 & 12.2 & 8.6 & 3.6 \\
\hline Glycemic level $(\mathrm{mg} / \mathrm{dl})^{\dagger}$ & 68 & 165.4 & 59.6 & 10.7 & 4.7 \\
\hline Triglycerides $(\mathrm{mg} / \mathrm{dl})^{\ddagger}$ & 68 & 205.0 & 132.2 & 15.0 & 7.0 \\
\hline HDL-cholesterol $(\mathrm{mg} / \mathrm{dl})^{\ddagger}$ & 12 & 46.7 & 8.0 & 12.5 & 4.9 \\
\hline Men & 6 & 41.5 & 8.4 & - & - \\
\hline Women & 6 & 51.8 & 2.3 & - & - \\
\hline
\end{tabular}

SD: Standard deviation. * $\Delta \mathrm{T}$ : Period of time, in months, between last medical records and at the time of patient inclusion in the study. **Systolic and Diastolic Blood Pressure values from medical records from the last physician evaluation. $\dagger$ Glycemic level value from medical records from the most recent laboratory blood tests. $\$$ Triglyceride and HDL-cholesterol values from medical records from the last laboratory blood tests. 
Table 6 - Descriptive values of medicines prescribed to the 75 included patients

\begin{tabular}{lccccc}
\hline Variable & Mean & Standard deviation & Median & Min & Max \\
\hline No. of medicines & 4.2 & 1.9 & 4.0 & 1.0 & 9.0 \\
No. of tablets/day & 7.0 & 4.5 & 6.0 & 1.0 & 24.0 \\
Dose frequency (times/day) & 2.2 & 0.6 & 2.0 & 1.0 & 3.0 \\
\hline
\end{tabular}

Table 7 - Number and percentage of patients by prescribed drug category

\begin{tabular}{lcc}
\hline Prescribed drugs & $\begin{array}{c}\text { Number of patients } \\
(\mathrm{n}=75)\end{array}$ & $\%$ \\
\hline Antihypertensive agents & 74 & 98.6 \\
Oral hypoglycemic agents & 69 & 92.0 \\
Acetylsalicylic acid & 23 & 30.6 \\
Insulin & 16 & 21.3 \\
Antilipemic agents & 13 & 17.3 \\
Antiulcer agents & 12 & 16.0 \\
Central Nervous System drugs & 8 & 10.6 \\
Thyroid hormones & 5 & 6.8 \\
Antiglaucomatous agents & 1 & 1.3 \\
\hline
\end{tabular}

(45.3\%) patients said that they had no expense related to their medication, and $26(34.7 \%)$ spent up to $10 \%$ of their total family income on medicines. Regarding the level of difficulty in getting their prescriptions filled, 67 (89.3\%) patients said that they considered this an easy task. Table 6 presents the descriptive values of the number of different prescribed medicines, the number of tablets and dose frequency. Table 7 shows the number of patients for each category of prescribed drugs.

Seventy (93.3\%) patients had the responsibility of managing their medication by themselves and 67 (89.3\%) patients believed that taking medicines did not disturb their daily routine (56 patients) or that it disturbed their routine only a little (11 patients).

Characteristics related to the level of knowledge of cardiovascular risk factors. Among the 75 patients evaluated, 35 (46.6\%) exhibited a good level of knowledge about cardiovascular risk factors (correct answers $\geq 75 \%$ ), while $24(32.0 \%)$ patients had only a moderate level of knowledge $(50 \%<$ correct answers $<74.9 \%)$. Ten $(13.4 \%)$ patients exhibited a low level of knowledge $(25 \%<$ correct answers $<49.9 \%)$ and 6 others $(8.00 \%)$ demonstrated a very low level of knowledge (correct answers $\leq 24.9 \%$ ). Figure 1 shows the average distribution of percentages of correct answers for each cardiovascular risk factor assessed.

\section{PATIENT COMPLIANCE AND ASSOCIATION BETWEEN VARIABLES}

Patients showed high compliance with their drug treatment, with an average score of 5.44 points $(S D=0.68)$.

The association analysis between independent variables and compliance gave the following results:

- Variables related to access to medicines: mode of acquisition of medicines (completely or partially from SUS; Mean \pm SD: $5.42 \pm 0.79$ vs. $5.47 \pm 0.52 ; \mathrm{p}=0.876$ ),

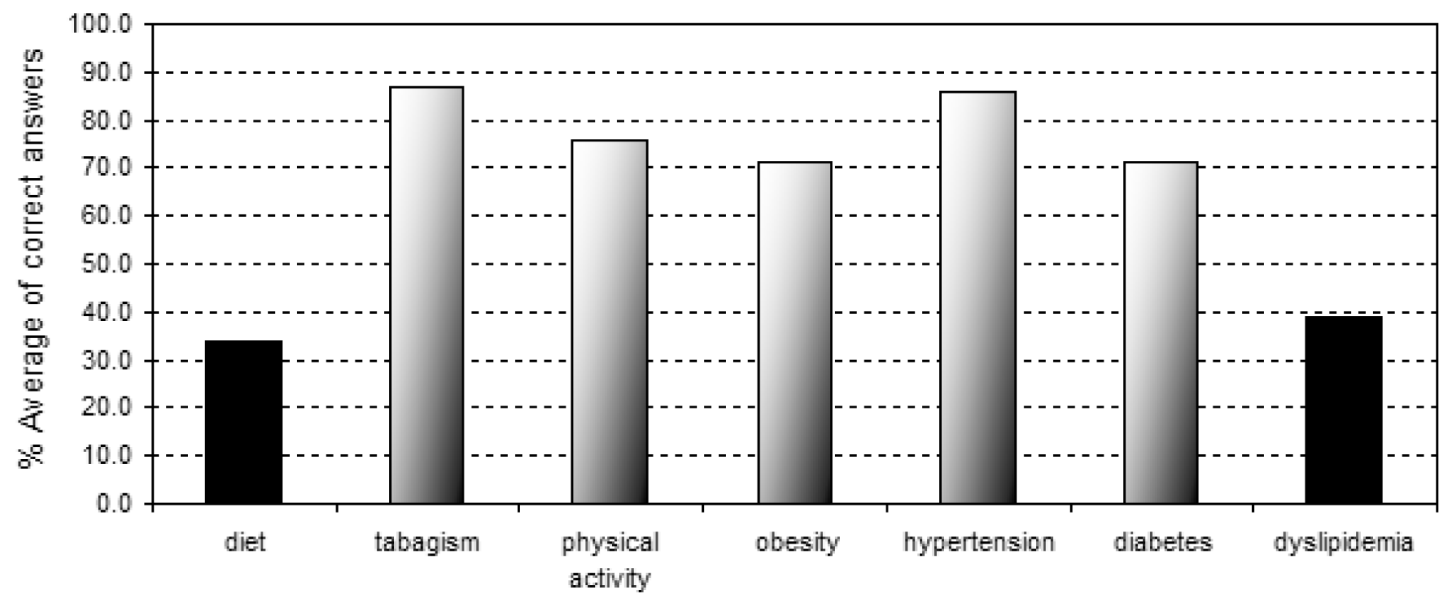

Cardiovascular risk factors

Figure 1 - Patient knowledge about cardiovascular risk factors: \% average of correct answers of 75 patients 
degree of difficulty in getting prescriptions filled (moderate or easy; Mean \pm SD: $5.69 \pm 0.43$ vs. $5.41 \pm 0.70$; $\mathrm{p}=0.124)$ and expense of medicines compared to total family income ( $0 \%$ of the family income, up to $10 \%$ of family income, and $>10 \%$ of family income; Mean \pm SD: $5.48 \pm 0.38$ vs. $5.29 \pm 1.01$ vs. $5.78 \pm 0.26 ; \mathrm{p}=$ 0.136 ). None of these variables showed an association with compliance with drug treatment.

- Variables related to the use of medicines: there was no association between the number of medicines $(\mathrm{p}=$ $0.976)$, number of tablets/day $(\mathrm{p}=0.964)$ and daily dose frequency $(\mathrm{p}=0.913)$ and compliance. Similarly, there was no association between responsibility for managing medication and compliance (patient or caregiver; Mean \pm SD: $5.43 \pm 0.69 v s .5 .57 \pm 0.55 ; \mathrm{p}=0.560$ ). Patients who said that taking medicines has disturbed their daily routine did not show degree of compliance significantly different from those who negatively answered this question $($ Mean \pm SD: $5.29 \pm 0.61$ vs. $5.57 \pm 0.35 ; \mathrm{p}=0.115)$.

- The level of knowledge about cardiovascular risk factors: there was no association with patient compliance with drug treatment, even when each cardiovascular risk factor was considered on its own.

\section{DISCUSSION}

In the present study, all data were collected from the medical records of 483 hypertensive and/or diabetic patients who were registered in a Health-Medical School Center associated with the Public Brazilian Healthcare System (SUS). There was a lack of data to identify patients with metabolic syndrome, such as waist circumference and HDL-cholesterol levels. This suggests that the concept of metabolic syndrome is not well established in the clinical practice at the Health-Medical School Center where this study was performed. As a matter of fact, there are many controversies about this condition that are related to the existence of several definitions for metabolic syndrome, its pathophysiological mechanism, its value as a good predictor of diabetes or cardiovascular disease and even whether or not it is truly a syndrome. ${ }^{22-26}$

Compliance with drug treatment evaluation may be performed by direct methods (directly observed therapy, measurement of the level of medicines or metabolites in blood and measurement of biological markers in blood) and indirect methods (assessment of patient clinical response, rates of prescription refills, pill counts, electronic medication monitors and information collected from health professionals or patients, such as questionnaires and self-reports). ${ }^{27}$ No method is considered to be the gold standard. ${ }^{20,27}$ Direct methods are objective and accurate, but expensive. ${ }^{27}$
Indirect methods are easy to use, but subjectivity may be a disadvantage. ${ }^{14}$

Evaluating compliance by assessing patient clinical response supposes a direct association between compliance and the expected clinical results. Patient health problems may be resolved or be controlled for reasons other than compliance with drug treatment. ${ }^{20}$ Patients may also be compliant with drug treatment but still not show the desired result. Clinical results may be used as a measure of compliance when the treatment is related to a specific clinical result, for example, glycemic or blood pressure levels. However, some authors consider the occurrence of the "effect of toothbrush", i.e., the patient is compliant with the treatment only immediately before visiting the doctor. ${ }^{20}$

Questionnaires and self-reports are susceptible to distortion. Patients generally want to please their physicians and will often say what they think their doctor wants to hear. ${ }^{20,27}$ Aiming at overcoming these biases and obtaining a method that is easy to use and suitable for different situations, the Morisky-Green Test was developed. ${ }^{28}$ It is composed of four questions that allow dichotomous answers ("yes" or "no"). Patients are considered to be compliant with treatment when they answer negatively all questions. According to the authors, considering negative answers as the valid ones should reduce the problem of patients overestimating compliance. ${ }^{28}$

In this study, compliance was evaluated using a variation of the Morisky-Green Test ${ }^{28}$ that had the advantage of making alternatives to answers in the Likert Scale possible. This makes the test significantly more sensible, allowing for the detection of situations of non-adherence..$^{20}$

A high compliance level with drug treatment was verified. This is not in accordance with other compliance studies using the same types of drugs. Studies with antihypertensive agents showed compliance levels between $50 \%$ and $70 \%$. During the first year of treatment, from $16 \%$ to $50 \%$ of patients gave up the treatment. ${ }^{14}$ Regarding antilipemic agents, it is estimated that only $50 \%$ of patients who were being treated with statins continue to use their medication after six months, and only $30 \%$ to $40 \%$ are taking them after one year. ${ }^{29}$ Additionally, a study that used the Morisky-Green Test to evaluate compliance with diabetes treatment showed that $51 \%$ of diabetic patients were considered to be non-adherent. ${ }^{30}$

Therefore, it is important to take into consideration the possibility that the patients who decided to participate in this study were naturally compliant. In this case, statistically significant differences between blood glucose and pressure levels should have been observed. Patients who scheduled an appointment for the research should have presented with better blood glucose and pressure levels than those who 
did not. However, this was not confirmed. Another relevant point to be considered is the possibility that patients may overestimate their compliance.

Compliance is a multidimensional phenomenon determined by the interplay of five sets of factors: socioeconomic factors; therapy-related factors; condition-related factors; patient-related factors; and healthcare team and systemrelated factors. ${ }^{14}$ Although socioeconomic factors have not consistently been found to be an independent predictor of compliance, low socioeconomic status may put patients in the position of having to choose between competing priorities. ${ }^{14}$ In this scenario, the cost of medicine is a key issue for compliance levels. ${ }^{31}$ Financial restrictions may lead patients to total or partial interruption of their treatments. ${ }^{32}$ The scarcity of medicines is a factor even with the free distribution of essential medicines, including antihypertensive and oral hypoglycemic agents from the Public Brazilian Health System. In this study, $34.7 \%$ of patients spent up to $10 \%$ of their family income on medicine.

Considering that $66.7 \%$ of patients had low incomes, it was expected that even low expense for medicines would influence compliance levels. However, there was no association between the level of expense of medicine and compliance. It is important to consider the limited number of patients and the absence of another comparative group.

Regarding therapy-related factors, some studies showed that compliance with drug treatment decreases as the number of different medicines, the number of pills and the dosage frequency ${ }^{33}$ increases. Nevertheless, this study found no association between these variables and compliance.

Patient-related factors, such as knowledge and beliefs about their disease, motivation to manage it and expectations regarding the outcome of treatment, interact in ways not yet fully understood to influence compliance behavior. ${ }^{14}$ This study did not find an association between knowledge of cardiovascular risk factors and compliance.

Together, these findings suggest the existence of a specific compliance behavior profile that is characteristic of the studied patients, but independent of the analyzed variables. It may be related to the multidisciplinary approach the patient adopted at the Health-Medical School Center where the research was performed. However, this hypothesis was not tested in this study. The multidisciplinary approach has been recognized as an effective contributory factor for improving compliance levels. ${ }^{27,31}$ In spite of this approach, its application on a daily basis demands continual effort, self-discipline and teamwork by health professionals. ${ }^{31}$ As these challenges are met, the multidisciplinary approach is considered to be part of the health system's daily routine, and elevated compliance levels are possible.

This study also identified a lack of knowledge of cardiovascular risk factors, mainly diet and dyslipidemia. Knowledge about disease or treatment does not guarantee patient compliance,${ }^{34}$ but it is an important factor in active patient participation in decisions that involve his/her health condition. ${ }^{35}$ From this point of view, there may be an opportunity to promote cardiovascular risk reduction. The adoption of educational strategies that improve patient knowledge of cardiovascular risk factors may give them an incentive to actively participate in their treatment and to make treatment success more tangible. This may be the first step in effectively introducing diet and regular practice of physical activity in daily routines, once these activities are associated with significant clinical improvements. ${ }^{36}$ Finally, better knowledge of cardiovascular risk factors may lead to more rational utilization of financial resources.

\section{CONCLUSIONS}

Patients with metabolic syndrome who were being treated in a Health-Medical School Center with antihypertensive, antilipemic and antidiabetic agents, have demonstrated a high level of drug compliance. There were no statistically significant associations between access to and use of medicines and level of knowledge of cardiovascular risk factors and compliance. Patients included in this study also demonstrated a low knowledge of diet and dyslipidemia; this may have implications for non-drug treatment and for the reduction of cardiovascular risk. However, this hypothesis needs further investigation. More research is needed to confirm if the high level of compliance found in this study is characteristic of patients treated in a Health-Medical School Center in comparison with patients treated in other public or private healthcare centers. Additionally, it might be especially elucidative to have comparative studies enrolling patients with metabolic syndrome as well as other patient groups with diagnoses of isolated hypertension, diabetes and dyslipidemia.

\section{REFERENCES}

1. Third report of the national cholesterol education program (NCEP) expert panel on the detection, evaluation, and treatment on high blood cholesterol in adults (Adult Treatment Panel III). Final report. II Rationale for intervention. Circulation. 2002;106:3188-90.
2. World Health Organization. Definitions, diagnosis and classification of diabetes mellitus and its complications. Report of a WHO Consultation. Part I: Diagnosis and classification of diabetes mellitus. Geneva: WHO, 1999. 
3. Ford ES, Giles WH, Mokdad AH. Increasing prevalence of the metabolic syndrome among U.S Adults. Diabetes Care 2004;27:2444-9.

4. Gupta R, Deedwania PC, Gupta A, Rastogi S, Panwar PB, Kothari C. Prevalence of metabolic syndrome in an Indian urban population. Int $\mathrm{J}$ Cardiol 2004;97:257-61.

5. Brandão AP, Brandão AA, Berenson GS, Fuster V. Síndrome metabólica em crianças e adolescentes. Arq Bras Cardiol 2005;854:79-81.

6. Lorenzo C, Williams K, Hunt KJ, Haffner SM. National Cholesterol Education Program - Adult Treatment Panel III, International Diabetes Federation, and WHO definitions of the metabolic syndrome as predictors of cardiovascular disease and diabetes. Diabetes Care 2007;30:8-13.

7. Bahia L, Aguiar LG, Villela N, Bottino D, Godoy-Matos AF, Geloneze B, et al. Relationship between adipokines, inflammation, and vascular reactivity in lean controls and obese subjects with metabolic syndrome. Clinics. 2006;61:433-40.

8. Fujioka K. Metabolic syndrome treatment strategies. Pharmacotherapy 2006;26:222S-6S

9. Israili ZH, Lyoussi B, Hernandez-Hernandez R, Veslasco M. Metabolic syndrome: treatment of hypertensive patients. Am J Therap 2007; 14:386402 .

10. Grundy SM. Controversy in clinical endocrinology. Metabolic syndrome: a multiplex cardiovascular risk factor. J Clin Endocrinol Metab 2007;92:399-404.

11. Luz PL, Bertini PJ, Favarato D. Noninvasive detection of coronary artery disease - challenges for prevention of disease and clinical events. Clinics 2005;60:415-28.

12. DiMatteo MR, Giordani PJ, Lepper HS, Groghan TW. Patient adherence and medical outcomes: a meta-analysis. Medical Care 2002;40:794811.

13. Schroeder K, Fahey T, Ebrahim S. How can we improve adherence to blood pressure-lowering medication in ambulatory care? Systematic review of randomized controlled trials. Arch Intern Med 2004;164:72232.

14. World Health Organization. Adherence to long-term therapies: evidence for action. Geneva: WHO, 2003

15. Benner JS, Glyin RJ, Mogun H, Neuman PJ, Weinstein MC, Avorn J. Long-term persistence in use of statin therapy in elderly patients. JAMA 2002;288:455-61.

16. Cramer J. A systematic review of adherence with medications for diabetes. Diabetes Care 2004;27:1218-24.

17. Rasmussen JN, Chong A, Alter DA. Relationship between adherence to evidence-based pharmacotherapy and long-term mortality after acute myocardial infarction. JAMA 2007;297:177-86.

18. Zimmet P, Alberti G, Shaw J. A new IDF worldwide definition of the metabolic syndrome: the rationale and the results. Diabetes Voice 2005;50:31-3.

19. Khan MS, Jafary FH, Jafar TH, Faruqui AM, Rasool SI, Hatcher J et al. Knowledge of modifiable risk factors of heart disease among patients with acute myocardial infarction in Karachi, Pakistan: a cross sectional study. BMC Cardiovasc Disord. 2006;6:18. Published online 2006 April 27. doi: 10.1186/1471-2261-6-18.
20. Delgado AB, Lima ML. Contributo para a validação concorrente de uma medidade de adesão aos tratamentos. Psicologia, Saúde \& Doenças. 2001, 281-100.

21. I Diretriz Brasileira de diagnóstico e tratamento da síndrome metabólica. Hipertensão 2004;7:123-59.

22. Zimmet PZ, Alberti G. The metabolic syndrome: perhaps an etiologic mystery but far from a myth - Where does the international Diabetes Federation Stand? Medscape Diabetes \& Endocrinology 2005;7 (2). [cited 2006 Oct 31]. Available from: http://www.medscape.com/ viewarticle/514211.

23. Kahn R, Buse J, Ferranini E, Stern M.The metabolic syndrome: time for critical appraisal. Joint statement from the American Diabetes Association and the European Association for the Study of Diabetes. Diabetologia 2005;48:1684-99.

24. Franks PW, Olsson T. Metabolic syndrome and early death: getting to the heart of the problem. Hypertension 2007;49:10-2.

25. Kahn R. metabolic Syndrome: Is it a syndrome? Does it matter? Circulation 2007;115:1806-11.

26. Tikhonoff V, Casiglia E. Metabolic syndrome: nothing more than a constellation? Eur Heart J 2007;28:780-81.

27. Osterberg L, Blaschke T. Adherence to medication. N Engl J Med 2005:353:487-97.

28. Morisky DE, Green LW, Levine DM. Concurrent and predictive validity of self-reported measure of medication adherence. Med Care 1986;24:67-74.

29. Third report of the national cholesterol education program (NCEP) expert panel on the detection, evaluation, and treatment on high blood cholesterol in adults (Adult Treatment Panel III). Final report. IX Adherence. Circulation. 2002;106:3359-66.

30. Krapek K, King K, Warren SS, George KG, Caputo DA, Mihelich K et al. Medication adherence and associated hemoglobin A1c in type 2 diabetes. Ann Pharmacother. 2004;38:1357-62.

31. V Diretrizes Brasileiras de Hipertensão Arterial. Arq Bras Cardiol. 2007;89:e24-79.

32. Rocha Jr. MA. Compliance - você acha que a receita vai ser seguida?. In: Zanini AC, Paulo LG. Compliance: sobre o encontro paciente-médico. São Paulo: Ipex. 1997;4:51-66.

33. Iskedjian M, Einarson TR, Mackeigan LD, Shear N, Addis A, Mittmann $\mathrm{N}$ et al. Relationship between daily dose frequency and adherence to antihypertensive pharmacotherapy: evidence from a meta-analysis. Clin Ther. 2002,24:302-16

34. Chan YM, Molassiotis A. The relationship between knowledge and compliance among Chinese with non-insulin dependent diabetes mellitus in Hong Kong. J Adv Nurs. 1999; 30:431-38.

35. Golin CE, Dimatteo MR, Gelber GL. The role of patient participation in the doctor visit. Implications for adherence to diabetes care. Diabetes Care. 1996;9:1153-64.

36. Fletcher B, Berra K, Ades P, Braun LT, Burke LE, Durstine JL et al. Managing abnormal blood lipids: a collaborative approach. Circulation. 2005; 112:3184-209. 